\title{
Movements of olive ridley sea turtles Lepidochelys olivacea and associated oceanographic features as determined by improved light-based geolocation
}

\author{
Yonat Swimmer ${ }^{1, *}$, Lianne McNaughton ${ }^{2}$, David Foley ${ }^{2}$, Lucas Moxey ${ }^{2}$, \\ Anders Nielsen ${ }^{2}$ \\ ${ }^{1}$ NOAA Fisheries, Pacific Island Fisheries Science Center, 2570 Dole Street, Honolulu, Hawaii 96822, USA \\ ${ }^{2}$ Joint Institute for Marine and Atmospheric Research, University of Hawaii, 1000 Pope Road, Honolulu, Hawaii 96822, USA
}

\begin{abstract}
We demonstrate the use of pop-off satellite archival tags (PSAT)-derived geolocations to determine the most probable tracks (MPTs) of olive ridley sea turtles Lepidochelys olivacea off Costa Rica. We use a Kalman filter state-space model (KFSST) that uses light-based longitude and latitude and sea surface temperatures (SST). PSATs placed on 14 turtles remained fixed for an average $53 \mathrm{~d}$ (range: 29 to $111 \mathrm{~d}$ ). The average reduction in longitude and latitude standard deviations was $\varphi_{\text {lon }}=$ 0.62 and $\varphi_{\text {lat }}=0.28$ between the raw and KFSST-derived MPTs, respectively. Geolocations were linked in time to oceanographic features such as SST and chlorophyll $a$, as reported by satellite-based sensors. Turtles went in all directions from their respective release points, independent of year and capture type (longline-caught vs. hand-caught). Turtles remained within a SST range between 23.3 and $30.5^{\circ} \mathrm{C}$ (mean $=27.1^{\circ} \mathrm{C}$ ), with over $75 \%$ of all recorded temperatures between 25.0 and $28.0^{\circ} \mathrm{C}$. Turtle locations were associated with mean chlorophyll $a=0.37 \mathrm{mg} \mathrm{m}^{-3}$. MPT data suggest that turtles spent a disproportionate amount of time in the general region of the Costa Rica Dome, a nutrientrich quasi-permanent cyclonic eddy. Taken together, these findings support the increased utility of filtered light-based geolocation data in identifying environmental features characteristic of sea turtles' preferred habitat, information which can be useful in managing regional fisheries.
\end{abstract}

KEY WORDS: Marine turtles · Geolocation · Pop-off satellite archival tags · Oceanographic features

\section{INTRODUCTION}

The use of electronic tags on fish and other marine fauna has offered insight into the movements and distribution of marine organisms, and has provided an opportunity to identify environmental factors associated with these movements (Arnold \& Dewar 2001, Polovina et al. 2001, Etnoyer et al. 2006, Godley et al. 2008). With this knowledge it is possible to predict, with varying degrees of confidence, the presence of species in a wide range of habitats, which can be a powerful tool for marine resource management efforts to balance conservation needs against activities such as commercial fishing (McDaniel et al. 2000, Howell et al. 2008). Refining these predicted movements is espe- cially important for commercial and protected species that have overlapping distributions, and advances in technology have increased the number of possibilities for acquiring such information (Fuller et al. 2008).

The evolution of tagging devices over the past few decades has yielded an expansive breadth of knowledge regarding numerous aspects of sea turtle ecology and behavior, including the spatial distribution of sea turtle species with transoceanic migrations (see review in Godley et al. 2008). Tags available for this type of research are plentiful and highly variable, ranging from low-tech methods such as metallic tags requiring the animals to be recaptured, to more advanced radio/sonic and satellite telemetry devices that can provide information on turtles' small or large-scale 
movement patterns remotely (Fuller et al. 2008, Godley et al. 2008). Because the cost of high-tech methods such as satellite telemetry is still relatively high, the number of units employed is often limited, thereby reducing studies to the movements of only a few animals (Godley et al. 2008).

The suite of satellite tags available for sea turtle telemetry studies include those that employ lightbased sensors from which an animal's geolocation must then be calculated. The benefits (primarily cost) and limitations regarding the use of light-based sensors on electronic tags for the purpose of geolocation have been reported for a number of marine fauna, including sea turtles (Fuller et al. 2008). Unlike conventional satellite tags that provide highly accurate geolocation by using Argos Doppler shift or Global Positioning System (GPS), light-based geographic position estimates are computed from the record of light intensity, from which estimates of dawn and dusk can be used to calculate longitude (from local noon) and latitude (from local day length) (Hill 1994, Musyl et al. 2001, Nielsen et al. 2006). When using lightbased sensors, factors that affect geolocation accuracy include (1) an animal's dive behavior, since accuracy decreases with increasing depth distribution (Musyl et al. 2003), and (2) time of year, i.e. the margins of error increase during the periods of an equinox because day length is nearly equal at all latitudes (Nielsen et al. 2006). Therefore, 'raw' (unfiltered) geolocations are often noisy and potentially inaccurate to hundreds of $\mathrm{km}$ (Nielsen et al. 2006). Due to the computations required, raw light-based geolocation estimates are less accurate than direct links to satellites (Fuller et al. 2008).

While considering these limitations, however, lightbased geolocation technology may be appropriate, especially when seeking information on animals' large-scale movement patterns and when high resolution may not be a research priority. Additionally, use of light-based tags may be less costly than of those with GPS technologies, thereby enabling the tracking of more individuals on a limited budget.

There are a number of techniques for light-based geolocation data that can result in more reliable estimates of an animal's true or actual position. One approach has been to use a Kalman filter state-space (KFSST) model that can effectively reduce the margin of error from the raw geolocation data (Sibert et al. 2003, Wilson et al. 2007). Precision of daily geolocation estimates can be further improved by incorporating sea surface temperature (SST) data into the model (Nielsen et al. 2006). The model essentially assumes that the tagged animal moves according to a biased random walk and that the raw geolocation positions are true positions plus some measurement error, thereby maximizing use of more reliable data (e.g. not those obtained during equinox periods). In its most recent version, the model includes longitude and latitude, as well as comparing SST measured by the tags and satellites, thereby improving the most probable tracks (MPTs) from geolocation estimates (Nielsen et al. 2006, Wilson et al. 2007).

In the present study, we demonstrate the use of popoff satellite archival tags (PSAT)-derived geolocation data to determine olive ridley turtles' MPTs by using a filtering model known as KFSST that uses longitude, latitude and SST. Based on the reconstructed MPT from each turtle, we identify key oceanographic features, such as SST and chlorophyll a (chl a), as well as regions of upwelling that characterize turtles' preferred habitat. Despite the limitations in the use of raw light-based geolocation data, our filtered data suggest its increased potential utility, especially for identifying large-scale movements and features associated with turtles' distribution in the Eastern Tropical Pacific (ETP), which we aim to characterize in this paper.

\section{MATERIALS AND METHODS}

Animal capture and tagging. We deployed 14 PSATs on olive ridley turtles Lepidochelys olivacea in the Gulf of Papagayo off the Pacific Coast of Costa Rica between November 2001 and June 2003 (Fig. 1). A total of 9 turtles had been incidentally captured in longline fishing gear and 5 were dip-netted while free-swimming at the surface prior to their capture. Information regarding turtles' size, location and date of tagging, and method of capture were recorded (see Table 1). All PSATs were attached to turtles using an epoxy method (Swimmer et al. 2002), except for 2 PSATs that were bolted to turtles' postcentral scutes (Epperly et al. 2007). For the analysis of geolocation data, the first and last positions are fixed points for turtles' release and pop-up points. The time between these 2 points is considered to be the number of days the animal was at liberty.

PSATs used were Wildlife Computers PAT2 tags and Microwave Telemetry PTT-100 tags. Wildlife Computer (WC) tags were programmed using PATHOST software to record pressure (i.e. depth, m), light level, and temperature $\left({ }^{\circ} \mathrm{C}\right)$ every $60 \mathrm{~s}$, and to store the data in 12 depth and temperature bins covering ranges from 0 to $1000 \mathrm{~m}$ and 5 to $60^{\circ} \mathrm{C}$, respectively. They were also programmed to record maximum daily dive depth and to release from the animal $1 \mathrm{yr}$ after deployment. Microwave Telemetry (MT) tags were programmed to record temperature and pressure (depth) readings every hour and to release from the animal 8 mo after deployment. Daily geolocation estimates were ob- 

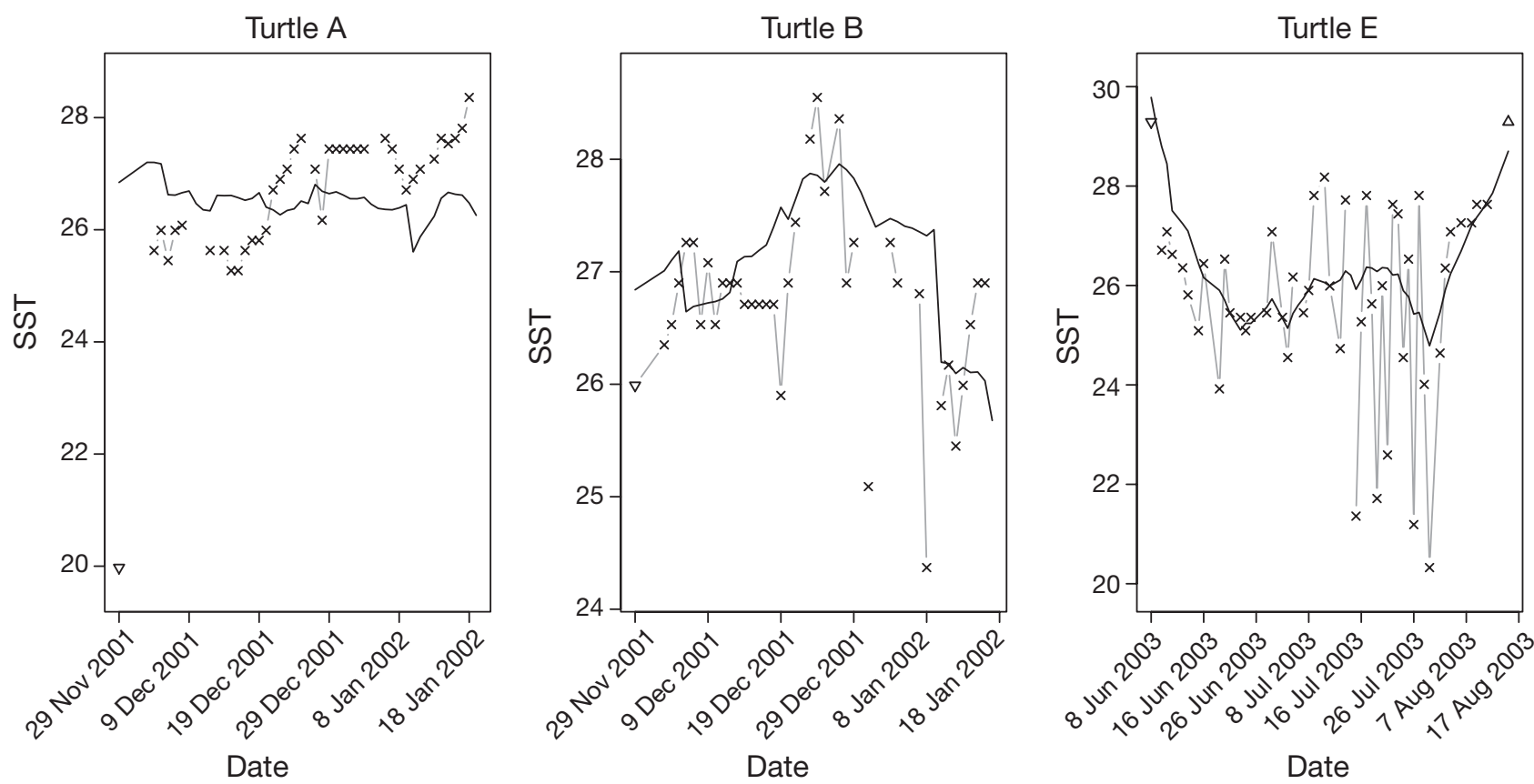

Fig. 1. Lepidochelys olivacea. Daily median sea surface temperature (SST) measurements (crosses) obtained directly from the pop-off satellite archival tags (PSAT) compared to satellite-derived smoothed SST (black line) for 3 olive Ridley turtles

tained from the light and temperature data from the WC tags using manufacturer-supplied software. For the MT tags, estimates for dawn and dusk were automatically calculated in the tag by a proprietary algorithm, and daily geolocation estimates were supplied by the tag manufacturer (Gunn \& Block 2001).

Modeling most probable tracks. We used KFSST models (Nielsen et al. 2006) to compute turtles' most probable tracks, and hence distance traveled, for all turtles from which we received data. Daily median SST measurements in the tag were taken from the surface to $17 \mathrm{~m}$ and compared to satellite derived SSTs. Because the SST from the satellite images are available in a grid of points, we followed a track and determined the associated satellite SST at each point along the track. In order to interpolate the data, we smoothed the closest points in the grid in order to generate SST at a certain point on the track (Fig. 1).

The KFSST model provides estimates of the uncertainty in the raw geolocations as well as the uncertainty in the points on the most probable track. To obtain a quantitative estimate of the improvement in the track between the raw data and the MPT generated by the model, we used the fraction of the average standard deviations for both latitudinal and longitudinal errors. For example, for a given track's longitude, we computed: For example, for a given track's longitude, we computed: $\varphi$ lon $=\sigma_{\text {lon,MPT }} / \sigma_{\text {lon,raw }}$, where $\sigma_{\text {lon,MPT }}$ is the average of the estimated standard deviations of the geolocations of the MPT and $\sigma_{\text {lon,raw }}$ is the average of the estimated standard devia- tions of the raw geolocations. For latitude, $\sigma_{\text {lat }}$ is similarly defined.

Coupling turtles' tracks to oceanographic features. Turtles' MPTs were overlaid with corresponding satellite remote sensing oceanographic data provided by the NOAA/National Environment Satellite, Data and Information Service (NESDIS) Coastwatch and OceanWatch programs. SST data were derived from Advanced Very High Resolution Radiometers (AVHRR) on board the NOAA polar orbiting satellites. Data prior to July 2003 were obtained from the descending nighttime passes (Vazquez et al. 1998) and received as a 9 $\mathrm{km}$ product mapped to an equal area projection for each 8 d period. From July 2003 to present, daily SST data processed using the NESDIS global area coverage (GAC) algorithm were averaged to create weekly and monthly images that are comparable on a temporal and spatial resolution to the Pathfinder V4 SST product $\left(\mathrm{r}^{2}=0.99, \mathrm{p}<0.01\right)$

\section{RESULTS}

Of the 14 tags deployed, 3 failed and the remaining 11 transmitted successfully for a mean 53 d (range: 29 to $111 \mathrm{~d}_{i}$ Table 1). One tag did not report SST data, and therefore our modeling efforts were limited to 10 tracks. In total, the 10 PSATs placed on olive ridley turtles provided 708 light-based geolocation estimates, from which 335 daily estimates of the animals' most probable tracks were determined (Fig. 2). Based on 
calculated MPTs, turtles traveled an average of 1807 $\mathrm{km}$ per track, averaging $\sim 42 \mathrm{~km}$ per turtle $\mathrm{d}^{-1}$ (range: 18 to 105). There were no apparent differences in posthooking deployment distance traveled or directionality between turtles that had been hooked (mean $=45 \mathrm{~km}$ $\mathrm{d}^{-1}, \mathrm{SD}=11.37$, range: 18 to $107 \mathrm{~km}, \mathrm{n}=7$ ) or caught when free-swimming (mean $=40 \mathrm{~km} \mathrm{~d}^{-1}, \mathrm{SD}=19.10$, range: 22 to $64 \mathrm{~km}, \mathrm{n}=4$ ) (Table 1 ).

Raw unfiltered PSAT geolocation data and MPTs were compared for all turtles, with representative tracks illustrating the improvement in precision shown in Figs. 2 \& 3 . The average reduction in longitude and latitude standard deviations was $\varphi_{\text {lon }}=0.62(\mathrm{SEM}=0.060)$ and $\varphi_{\text {lat }}=$ $0.28(\mathrm{SEM}=0.033)$ between the raw and KFSST-derived MPTs, respectively (Table 1). The $95 \%$ confidence intervals of 2 turtles are illustrated in Fig. 4.

Turtles' movements remained in SSTs between 23.3 and $30.5^{\circ} \mathrm{C}$ (mean $=27.1^{\circ} \mathrm{C} ; \mathrm{SE}=0.27$ ), with over threequarters of all recorded temperatures between 25.0 and $27.9^{\circ} \mathrm{C}$ (Table 1 ; Figs. 3, $5 \& 6$ ). One individual (Turtle 29474) that was tracked in the fall was associated with higher chl a levels (mean $=0.69 \mathrm{mg} \mathrm{m}^{-3}$; $\mathrm{SEM}=0.166$; range: 0.160 to 1.93 ) than the remaining 9 turtles, which were located in mean $0.37 \mathrm{mg} \mathrm{m}^{-3}$ $(\mathrm{SEM}=0.042$; range 0.19 to 0.52 ) (Table 1 ; Fig. 3). Excluding Turtle 29474 from the group mean, 62\% of all determined turtle locations were within the chl $a$ range 0.2 to $0.6 \mathrm{mg} \mathrm{m}^{-3}$.

We investigated the frequency of SSTs associated with olive ridley turtles' MPTs in relation to the distribution of available temperatures in the vicinity of the study. Turtles' mean daily associated SSTs in $1^{\circ} \mathrm{C}$ bins (e.g. ' $24^{\prime}=24.0$ to $24.9^{\circ} \mathrm{C}$ ) are presented next to mean weekly average SST for the geographic range covering 8 to $13^{\circ} \mathrm{N}$ and 86 to $91^{\circ} \mathrm{W}$ for periods during which a minimum of 1 turtle was tracked for the duration of the study period (29 Nov 2001 to 9 Jan 2002, 5 Apr to 27 Jul 2003, 2 Sep to 30 Oct 2002, 2 Dec 2002 to 30 Jan 2003, 8 Jun to 15 Aug 2003) (Fig. 6).

The only turtle (E) tracked during summer months was associated with relatively low levels of chl a (mean $\left.\sim 0.20 \mathrm{mg} \mathrm{m}^{-3}\right)$ within the most restricted range $(0.15$ to $0.40 \mathrm{mg} \mathrm{m}^{-3}$ ), while the one turtle tracked during the fall (Turtle 29474) was associated with the highest mean chl a levels (mean $=0.69 \mathrm{mg} \mathrm{m}^{-3}$, range: 0.16 to $1.93 \mathrm{mg} \mathrm{m}^{-3}$ ).

\section{DISCUSSION}

Incorporation of information on environmental correlates to turtles' movement patterns and habitats can play an important role in the management of marine areas. The identification of species' habitat preferences, either by tracking movements or modeling, has been identified as a powerful conservation tool in ecosystem management. Specifically, the application of findings can help to effectively reduce the interaction rates between protected species (e.g. sea turtles, cetaceans) and fisheries, assist in the creation of effective and minimal time-area fishing closures, and to maintain the integrity of the marine ecosystem (Canadas et al. 2005, Kobayashi et al. 2008).

In the present study, we used pop-up satellite

Table 1. Lepidochelys olivacea. Tag and turtle data for olive ridley turtles. Catch method: control turtles were hand-caught while free-swimming, longline turtles were those that were retrieved from shallow-set longline fishing gear. Tag: tag manufacturer, MT: Microwave Telemetry, WC: Wildlife Computers. Days at liberty: Number of days tags remained on animal. Total distance: number of $\mathrm{n}$ miles (nautical miles) turtles traveled as measured by the most probable tracks (MPT). SST: sea surface temperature. N/A: not available (data not received)

\begin{tabular}{|c|c|c|c|c|c|c|c|c|c|c|c|}
\hline $\begin{array}{l}\text { Turtle } \\
\text { ID }\end{array}$ & $\begin{array}{c}\text { Date } \\
\text { deployed }\end{array}$ & $\begin{array}{l}\text { Catch } \\
\text { method }\end{array}$ & Tag & $\begin{array}{l}\text { Days at } \\
\text { liberty }\end{array}$ & $\begin{array}{c}\text { Total } \\
\text { distance } \\
\text { (n miles) }\end{array}$ & $\begin{array}{c}\text { Mean } \\
\text { daily } \\
\text { distance } \\
\left(\mathrm{n} \text { miles d }^{-1}\right)\end{array}$ & $\begin{array}{c}\text { \% Days } \\
\text { geolocation } \\
\text { available }\end{array}$ & $\begin{array}{l}\text { Mean } \\
\text { SST } \\
(\mathrm{SEM})\end{array}$ & $\begin{array}{l}\text { Mean } \\
\text { chl } a \\
\text { (SEM) }\end{array}$ & $\begin{array}{c}\text { Mean } \\
\text { estimated } \\
\text { SD MPT } \\
\text { (lon) }\end{array}$ & $\begin{array}{c}\text { Mean } \\
\text { estimated } \\
\text { SD MPT } \\
\text { (lat) }\end{array}$ \\
\hline A & 29 Nov 01 & Control & MT & 51 & 1482.7 & 29.1 & 94 & $26.3(0.09)$ & $0.49(0.026)$ & 0.567 & 0.320 \\
\hline B & 29 Nov 01 & Control & MT & 49 & 1078.2 & 22.0 & 92 & $27.0(0.12)$ & $0.50(0.019)$ & 0.371 & 0.140 \\
\hline $\mathrm{C}$ & 29 Nov 01 & Control & WC & 39 & 2519.8 & 64.6 & 49 & $27.5(0.10)$ & $0.52(0.037)$ & 0.885 & 0.341 \\
\hline $\mathrm{D}$ & 8 Jun 03 & Control & MT & N/A & N/A & N/A & N/A & N/A & N/A & N/A & N/A \\
\hline E & 8 Jun 03 & Control & MT & 68 & 3189.0 & 46.9 & 79 & $25.5(0.17)$ & $0.20(0.005)$ & 0.598 & 0.166 \\
\hline $\mathrm{F}$ & 28 Nov 01 & Longline & MT & N/A & N/A & N/A & N/A & N/A & N/A & N/A & N/A \\
\hline $\mathrm{G}$ & 29 Nov 01 & Longline & MT & 36 & 1839.0 & 51.1 & 92 & $26.5(0.09)$ & $0.45(0.015)$ & 0.714 & 0.390 \\
\hline $\mathrm{H}$ & 29 Nov 01 & Longline & WC & N/A & N/A & N/A & N/A & N/A & N/A & N/A & N/A \\
\hline I & 29 Nov 01 & Longline & WC & 30 & 1141.4 & 38.0 & 83 & $26.6(0.06)$ & 0.35 (0.019) & 0.652 & 0.286 \\
\hline $\mathrm{J}$ & 2 Sep 02 & Longline & MT & 58 & 1823.9 & 31.5 & 26 & $27.8(0.12)$ & $0.82(0.200)$ & 0.808 & 0.461 \\
\hline K & 2 Dec 02 & Longline & $\mathrm{MT}$ & 59 & 1056.2 & 18.0 & 92 & $28.0((0.07)$ & $0.19(0.013)$ & 0.444 & 0.217 \\
\hline $\mathrm{L}$ & 5 Apr 03 & Longline & $\mathrm{MT}$ & 49 & 1083.4 & 22.0 & 63 & $27.3(0.28)$ & $0.28(0.013)$ & 0.351 & 0.183 \\
\hline M & 6 Apr 03 & Longline & MT & 29 & 3113.0 & 107.4 & 38 & $28.1(0.29)$ & $0.38(0.97)$ & 0.815 & 0.313 \\
\hline $\mathrm{N}$ & 8 Apr 03 & Longline & MT & 111 & N/A & N/A & N/A & N/A & N/A & N/A & N/A \\
\hline
\end{tabular}



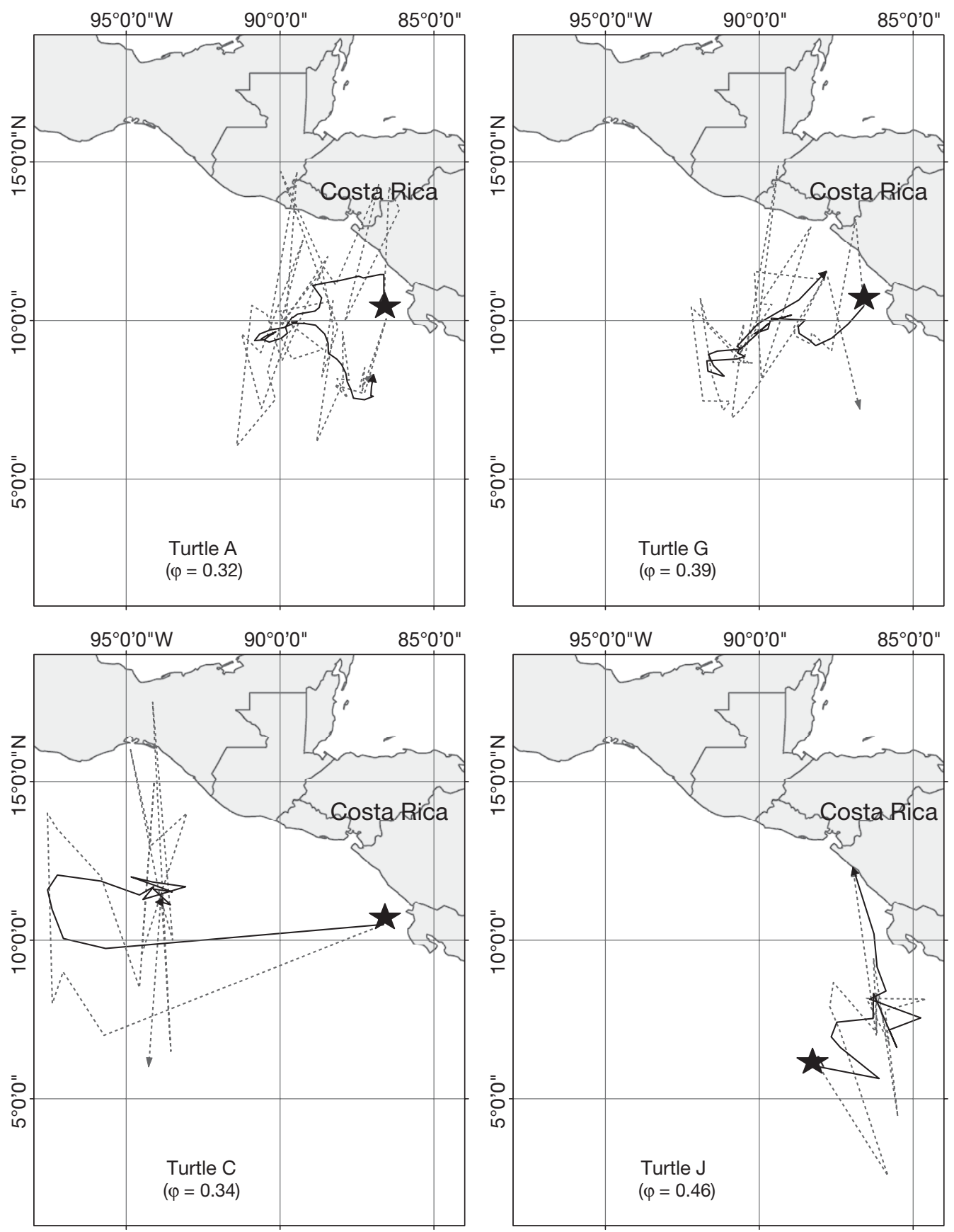

Fig. 2. Lepidochelys olivacea. Raw (dashed line) and most probable track (MPT) data (solid line) derived from Kalman filter statespace (KFSST) model for individual turtles from tag deployment locations (star). Associated $\varphi_{\text {lat }}$ value indicates confidence intervals for the estimates between 0.32 and 0.46

archival tags technology, which utilizes light-based geolocation technology, to determine the horizontal movement patterns and associated environmental features for olive ridley sea turtles in the ETP. PSATderived geolocations were used to determine olive ridley turtles' MPTs using a filtering model known as KFSST that uses longitude, latitude and SST. Based on the reconstructed tracks from each turtle, we identified key oceanographic features, such as SST, chl $a$, as well as regions of upwelling that characterize turtles' preferred habitat, thus suggesting the potential utility of light-based data to identify features associated with turtles' distribution in the region.

One of the limitations in using raw light-based 

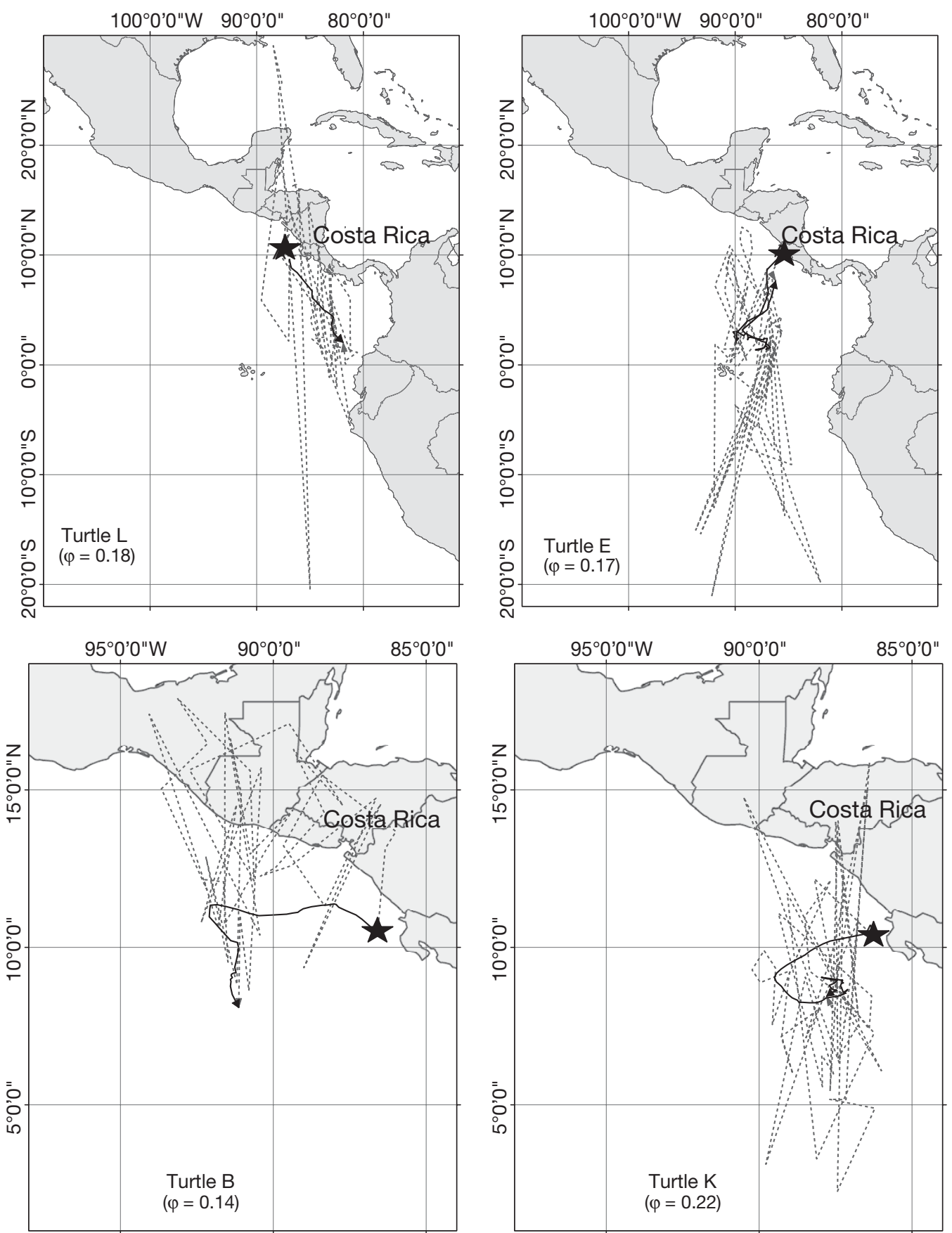

Fig. 3. Lepidochelys olivacea. Raw (dashed line) and most probable track (MPT) data (solid line) derived from KFSST model for individual turtles from tag deployment locations (star). Associated $\varphi_{\text {lat }}$ value indicates confidence intervals for the estimates between 0.14 and 0.22

geolocation data is that, unlike conventional satellite tags, geographic position estimates are computed from the record of light intensity, which can lead to questions of accuracy. Precision of raw estimates can be vastly improved through the use of the KSST filtering model; however, without the benefit of knowing an animal's true position, it is impossible to determine exactly how much accuracy is improved by using the most probable track from KFSST over the raw geolocations.

Here, we quantified the reduction in error estimates (a reflection of increased accuracy) between the raw PSAT geolocation data vs. the KFSST-derived MPTs by using a fraction of the average standard deviations for 


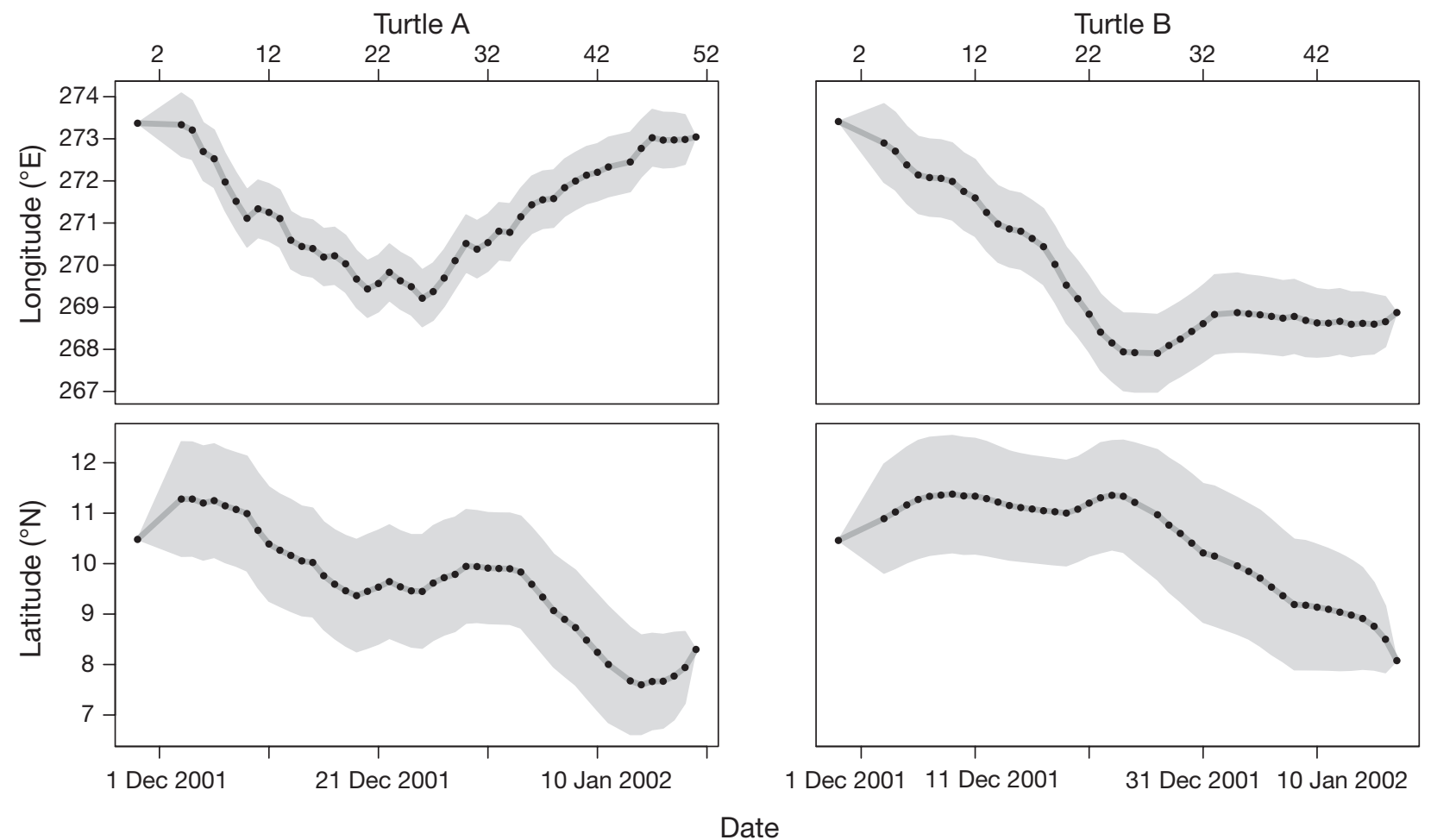

Fig. 4. Lepidochelys olivacea. Estimated most probable track (MPT) longitude (top panel) and latitude (bottom panel) of 2 olive ridley turtles. Shaded area is $95 \%$ confidence region, as estimated from the model. No. of days from day of deployment $(0)$ shown on top axis
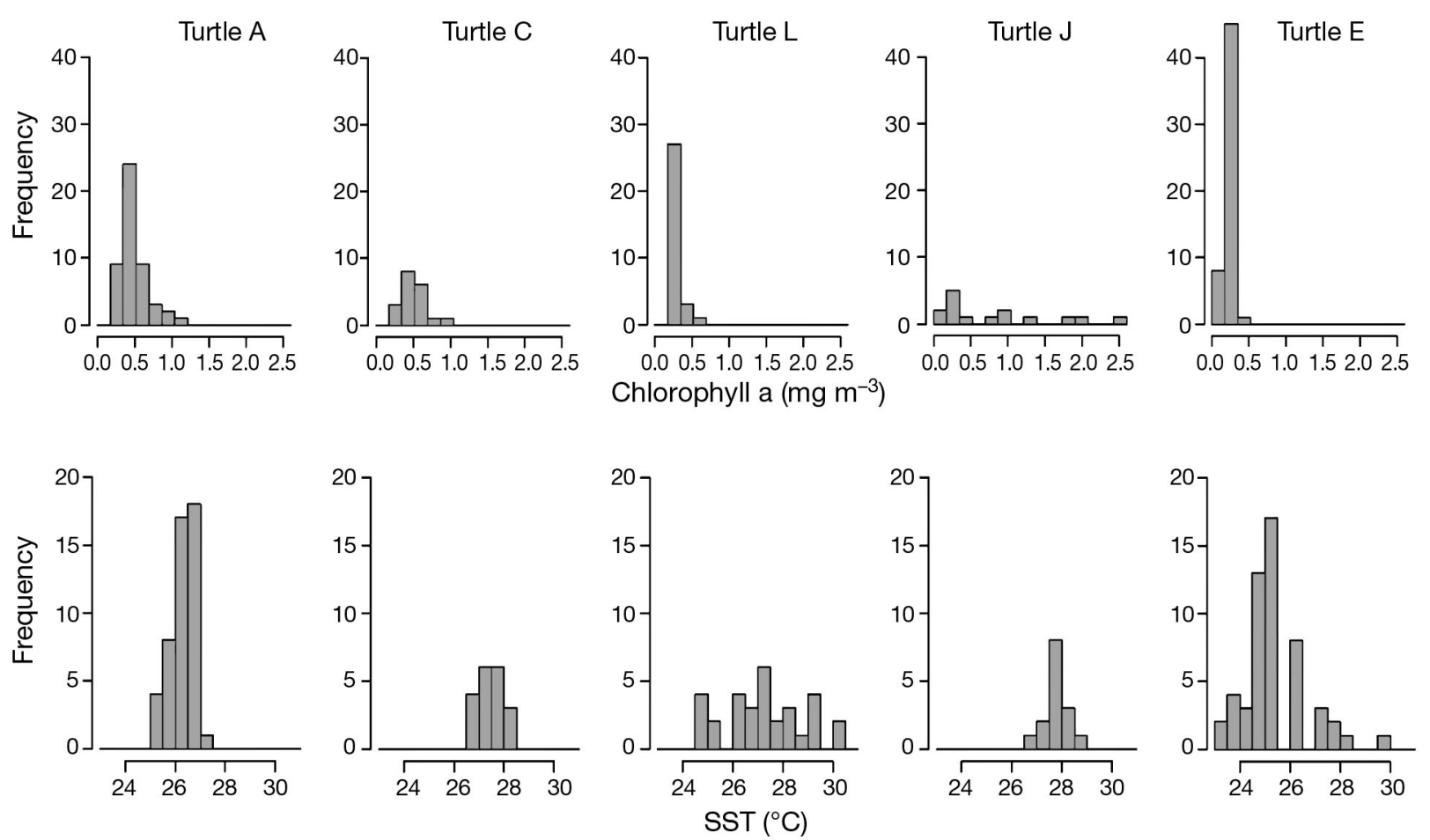

Fig. 5. Frequency distributions of sea surface temperatures (SST) and chl a for individual turtles (A, C, L, J, E) in the Eastern Tropical Pacific 


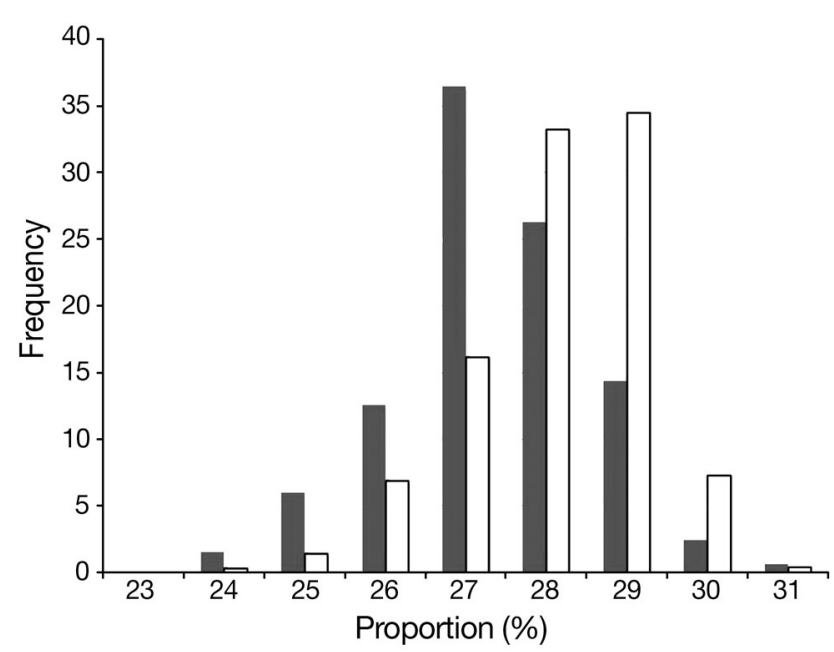

Fig. 6. Lepidochelys olivacea. Sea surface temperature (SST) readings from all turtles (open bars) and mean weekly average SSTs for the geographic area $\left(8\right.$ to $\left.13^{\circ} \mathrm{N}\right)$ and $\left(86\right.$ to $\left.91^{\circ} \mathrm{W}\right)$ and temporal period (29 Nov 2001 to 15 Aug 2003) in which turtles occurred (filled bars)

both latitudinal and longitudinal errors.

Our analysis calculated a mean value of $\varphi_{\text {lon }}=0.62$ and $\varphi_{\text {lat }} 0.28$, indicating that the confidence intervals for the estimates were reduced on average almost onehalf and one-quarter of their original lengths by using KFSST for longitude and latitude, respectively. By reducing the latitudinal error estimates by half, it seems justifiable to use the resulting turtle MPTs in a tracking study at the analysis level between fronts and eddies given the relatively large scale ( $\sim 0$ to $100 \mathrm{~km}$ ) (Figs. 1 $\& 2$ ). The accuracy of archival tag data before and after similar filtering efforts was recently reported by Wilson et al. (2007) whereby whale sharks Rhincodon typus tagged with both PSAT (light-based geolocation) and SAT (Argos-based satellite geolocation) tags resulted in overlapping tracks between modeled MPT and SAT data. Given these results, we are confident that the reconstructed MPTs lend themselves well to further understanding of environmental features, including thermal preferences, chlorophyll levels, and oceanographic fronts associated with sea turtle movements and distributions.

Information on a population's thermal 'preference' or defining boundaries within a specified thermal range can be instrumental in establishing measures to reduce the incidental and unwanted interactions of protected species that co-exist with target species (Kobayashi et al. 2008). For example, use of online real-time maps to characterize habitat utilization of loggerhead sea turtles have recently been developed to help reduce interactions between Hawaii-based longline fishing vessels and loggerhead turtles in the North Pacific Ocean. The movements of olive ridley turtles in the ETP are complex, with water temperatures assumed to play a primary role in influencing distributions (Plotkin 2003). Swimmer et al. (2006) previously described turtles' vertical movements, reporting that the turtles spent nearly $100 \%$ of their time in the top $60 \mathrm{~m}$, corresponding to temperatures between 22 and $28^{\circ} \mathrm{C}$. To more fully characterize a thermal 'preference', which can be achieved behaviorally by both altering vertical (e.g. dive patterns) and horizontal movements (Swimmer et al. 2006), we examined turtles' associated SSTs using AVHRR data associated with turtles' geolocations as determined by MPTs relative to available thermal habitats in their surroundings. Using data from a single day where turtles were tracked in a specific area, we marked the locations of 5 olive ridley turtles and found that despite a relatively wide range of available temperatures within 1 or $2 \mathrm{~d}$ swimming distance, all turtles remained in water with temperatures between 26 and $28^{\circ} \mathrm{C}$, suggesting preference for a limited range of temperatures. Polovina et al. (2004) previously described a high association of olive ridley turtles within the $27^{\circ} \mathrm{C}$ isotherm in the North Pacific Ocean and suggested a strong correlation with the distribution of suitable prey items, which is a likely phenomenon affecting the distribution of sea turtles in the ETP.

The role of chlorophyll and thermal structure in relation to marine turtle distributions is not clearly understood. Independent of other features such as prey abundance, chl a gradients alone are unlikely to drive the distribution of higher-trophic level organisms such as sea turtles. However, chl a gradients are associated with the abundance and distribution of other marine invertebrates known as prey items for olive ridley turtles. It has been speculated that olive ridley turtles may be opportunistic foragers, as similarly described for loggerhead turtles in the North Pacific and green turtles in the ETP (Polovina et al. 2001, Seminoff et al. 2008). Based on the generated MPTs for olive ridley turtles in this study, we found that in general, turtles were associated with chl a gradients $\sim 0.4 \mathrm{mg} \mathrm{m}^{-3}$, which were likely influenced by seasonal variability.

The question of olive ridley movements in relation to oceanographic fronts has been previously considered, with mixed results. While earlier studies speculated that sea turtles primarily used surface currents to aid in passive transport (Carr et al. 1978), later studies of satellite-tracked olive ridleys in the ETP and North Pacific Ocean provided evidence of turtles swimming against prevailing currents (Polovina et al. 2004, Beavers \& Cassano 1996). In studies on the foraging and migration habitats of sea turtles in the central North Pacific Ocean, Polovina et al. $(2001,2004)$ found clear associations between loggerhead turtles 
and fronts, eddies, and geostrophic currents. However, this relationship was not clearly defined for olive ridley turtles, perhaps in part due to difference in the genetic stock of the animals tracked, as speculated by the authors (Polovina et al. 2004). The data analyzed in the present study is also inconclusive with regard to olive ridleys' use of oceanic current. The MPT for Turtle B suggests that it followed the direction of predominant flow of the geostrophic currents existing at each point location throughout the course of its $49 \mathrm{~d}$ at liberty (minimum distance $=583$ nautical miles, $\mathrm{n}$ miles).

With respect to larger-scale, semi-permanent oceanic features or fronts, the ETP is well represented with currents. At approximately 8 to $10^{\circ} \mathrm{N}$ and 88 to $90^{\circ} \mathrm{W}$ there is an area of quasi-permanent cyclonic eddy. Termed the Costa Rica Dome, this area is characterized by an extremely shallow thermocline (within $10 \mathrm{~m}$ of the surface) and an area of upwelling, or divergence, resulting largely from wind-driven stress (Hoffman et al. 1981). The cyclonic circulation surrounding the Costa Rica Dome has been referred to as a 'hydrodynamic trap' because of its biodiversity and abundance of fish larvae transported from the shelf of Central America, where it intersects with the waters of the Costa Rica nearshore current (Evseenko \& Shtaut 2005).

Using MPT geolocation data, we investigated whether turtles in this study spent a disproportionate amount of time in the general region of the Costa Rica Dome near 8 to $10^{\circ} \mathrm{N}$ and 88 to $90^{\circ} \mathrm{W}$. We found that $36 \%$ of all turtle locations were in this relatively limited geographic range, thereby lending support to turtles' abundance in these regions of upwelled waters rich in prey items. Additionally, of the 10 turtles for which we generated MPTs, 5 (Turtles A, G, E, K, and J) remained within this general region for the majority of their time at liberty (Figs. 2 \& 3). Olive ridley turtles' associations with divergent fronts could have management implications, given that areas such as the Costa Rica Dome have been identified as important fishing grounds for tuna in the ETP (Hoffman et al. 1981). Use of light-derived MPTs for the purpose of examining large-scale associations, such as those within a $2^{\circ} \times 2^{\circ}$ grid, for example, could be an ideal means of defining 'hot spots' for improved monitoring and/or protective efforts.

This paper has identified the utility of PSATs by incorporating state-space Kalman filter models that include SST in order to determine animals' most probable tracks. By coupling data generated from this and other studies of turtle movements in the ETP with oceanographic remote sensing data, we can improve our understanding of animals' movement patterns in the marine environment. This will enable a more reli- able prediction of the distribution of both commercially valuable species (e.g. tunas) and protected species such as sea turtles in order to improve fisheries management efforts to reduce the interactions between fisheries and marine turtles.

Acknowledgements. We acknowledge extensive technical and administrative assistance from R. Arauz, J. Ballestero, R. Brill, C. Boggs, C. Empey Campora, D. Lau, L. Nakamura, M. Musyl, R. M. Laurs, B. Oshiro, and J. Sibert. This project was funded by the University of Hawaii Pelagic Fisheries Research Program (Grant \#658847) and by the Pacific Islands Fisheries Science Center, National Marine Fisheries Service, National Oceanic and Atmospheric Administration (JIMAR Fisheries Oceanography Grant \#658329). Chlorophyll data were provided by the SeaWiFS Project, NASA/Goddard Space Flight Center and GeoEye Inc. Pathfinder SST data provided by the PODAAC at NASA/Jet Propulsion Laboratory, California Institute of Technology. OSCAR currents were provided by NOAA Satellites and Information and Earth Space Research Inc. All research was conducted in accordance with the protocols and handling guidelines set forth by the University of Hawaii Animal Care and Use Committee (IACUC Protocol \# 00-037-2). R. Brill, E. Howell, M. Musyl, A. Southwood and J. Wang edited earlier drafts of this manuscript, but any errors of omission or commission are solely ours. Opinions expressed herein are those of the authors only and do not imply endorsement by any agency associated with the authors.

\section{LITERATURE CITED}

Alava JJ (2008) Loggerhead sea turtles (Caretta caretta) in marine waters off Ecuador: occurrence. Distribution and Bycatch from the Eastern Pacific Ocean. Mar Turtle Newsl 119:8-11

Arnold G, Dewar H (2001) Electronic tags in marine fisheries research: A 30-year perspective. In: Sibert J, Nielson J (eds) Electronic tagging and tracking in marine fisheries research: methods and technologies in fish biology and fisheries, Vol 1. Kluwer Academic Press, Dordrecht, p 7-64

Beavers S, Cassano ER (1996) Movements and dive behavior of a male sea turtle (Lepidochelys olivacea) in the Eastern Tropical Pacific. J Herpetol 30:97-104

Canadas A, Sagarminaga R, De Stephanis R, Urquiola E, Hammond PS (2005) Habitat preference modelling as a conservation tool: proposals for marine protected areas for cetaceans in southern Spanish waters. Aquat Conserv: Mar Freshw Ecosyst 15:495-521

Carr A, Carr MH, Meylan AB (1978) The ecology and migrations of sea turtles, 7 . The west Caribbean green turtle colony. Bull Am Mus Nat Hist 162:1-46

Epperly SP, Wyneken J, Flanagan JP, Harms CA, Higgins B (2007) Attachment of pop-up archival transmitting (PAT) tags to loggerhead sea turtles (Caretta caretta). Herpetol Rev 38:419-425

> Etnoyer P, Canny D, Mate BR, Morgan LE, Ortega-Ortiz JG, Nichols WJ (2006) Sea surface temperature gradients across blue whale and sea turtle foraging trajectories off the Baja California Peninsula, Mexico. Deep-Sea Res 53: 340-358

Evseenko SA, Shtaut MI (2005) On the species composition and distribution of ichthyoplankton and micronekton in 
the Costa Rica Dome and adjacent areas of the Tropical Eastern Pacific. J Icthyol 45:513-525

Fuller WJ, Broderick AC, Phillips RA, Silk JRD, Godley BJ (2008) Utility of geolocating light loggers for indicating atsea movements in sea turtles. Endang Species Res 4: 139-146

Godley BJ, Blumenthal JM, Broderick AC, Coyne MS, Godfrey MH, Hawkes LA, Witt MJ (2008) Satellite tracking of sea turtles: Where have we been and where do we go next? Endang Species Res 4:3-22

Gunn J, Block B (2001) Advances in acoustic, archival and satellite tagging of tunas. In: Block BA, Stevens ED (eds) Tuna physiology, ecology, and evolution. Fish Physiology Series, Vol 19. Academic Press, New York, p 167-224

Hill RD (1994) Theory of geolocation by light levels. In: LeBoeuf BJ, Laws RM (eds) Elephant seals: population ecology, behavior and physiology. University of California Press, Berkeley, CA, p 227-236

Hoffman EE, Busaluacchi AJ, O'Brien JJ (1981) Wind generation of the Costa Rica Dome. Science 214:552-554

Howell EA, Kobayashi DR, Parker DM, Balazs GH, Polovina JJ (2008) TurtleWatch: a tool to aid in the bycatch reduction of loggerhead turtles Caretta caretta in the Hawaii-based pelagic longline fishery. Endang Species Res 5:267-278

Kobayashi DR, Polovina JJ, Parker DM, Kamezaki N and others (2008) Pelagic habitat characterization of loggerhead sea turtles, Caretta caretta, in the North Pacific Ocean (1997-2006): Insights from satellite tag tracking and remotely sensed data. J Exp Mar Biol Ecol 356:96-114

McDaniel CJ, Crowder LB, Priddy JA (2000) Spatial dynamics of sea turtle abundance and shrimping intensity in the U.S. Gulf of Mexico. Conserv Ecol (1)4:15

Musyl MK, Brill RW, Boggs CH, Curran DS, Kazama TK (2001) Ability of archival tags to provide estimates of geographical position based on light intensity. In: Sibert JR, Nielsen JL (eds) Electronic tagging and tracking in marine fisheries reviews: methods and technologies in fish biology and fisheries. Kluwer Academic Press, Dordrecht, p 343-368

Musyl MK, Brill RW, Boggs CH, Curran DS, Kazama TK, Seki MP (2003) Vertical movements of bigeye tuna (Thunnus obesus) associated with islands, buoys, and seamounts near the main Hawaiian Islands from archival tagging

Editorial responsibility: Jeffrey Seminoff,

La Jolla, California, USA data. Fish Oceanogr 12:152-169

> Nielsen A, Bigelow KA, Musyl MK, Sibert JR (2006) Improving light-based geolocation by including sea surface temperature. Fish Oceanogr 15:314-325

Plotkin P (2003) Adult migrations and habitat use. In: Lutz P, Musick JA, Wyneken J (eds) The biology of sea turtles (Vol. 2). CRC Press, Boca Raton, FL, p 225-242

Polovina JJ, Howell E, Kobayashi D, Seki M (2001) The transition zone chlorophyll front, a dynamic global feature defining migration and forage habitat for marine resources. Prog Oceanogr 49:469-483

Polovina JJ, Balazs GH, Howell E, Parker DM, Seki M, Dutton P (2004) Forage and migration habitat of loggerhead (Caretta caretta) and olive Ridley (Lepidochelys olivacea) sea turtles in the central North Pacific Ocean. Fish Oceanogr 13:36-51

Seminoff JA, Zárate P, Coyne M, Foley DG, Parker D, Lyon BN, Dutton PH (2008) Post-nesting migrations of Galápagos green turtles Chelonia mydas in relation to oceanographic conditions: integrating satellite telemetry with remotely sensed ocean data. Endang Species Res 4:57-72

Sibert J, Musyl MK, Brill RW (2003) Horizontal movements of bigeye tuna (Thunnus obesus) near Hawaii determined by Kalman filter analysis of archival tagging data. Fish Oceanogr 12:141-151

Swimmer YJ, Brill RW, Musyl M (2002) Use of pop-up satellite archival tags to quantify mortality of marine turtles incidentally captured in longline fishing gear. Mar Turtle Newsl 97:3-7

Swimmer Y, Arauz R, McCracken M, McNaughton L, Ballestero J, Musyl M, Bigelow K, Brill R (2006) Diving behavior and delayed mortality of olive ridley sea turtles Lepidochelys olivacea after their release from longline fishing gear. Mar Ecol Prog Ser 323:253-261

Vazquez J, Perry K, Kilpatrick K (1998) NOAA/NASA AVHRR Oceans pathfinder sea surface temperature data set user's reference manual. Jet Propulsion Laboratory, Pasadina, $\mathrm{CA}$

- Wilson SG, Stewart BS, Polovina JJ, Meekan MG, Stevens JD, Galuardi B (2007) Accuracy and precision of archival tag data: a multiple- tagging study conducted on a whale shark (Rhincodon typus) in the Indian Ocean. Fish Oceanogr 16:547-554

Submitted: March 31, 2008; Accepted: October 16, 2008 Proofs received from author(s): February 4, 2009 